\title{
Profile of Patients with Stroke in Western Region of Nepal: A Hospital based Retrospective Study
}

\section{Buddhi Sagar Lamichhane ${ }^{1}$, Surya Bahadur Hamal Thakuri ${ }^{1}$ Rabi Mohan Dhakal ${ }^{2}$, Tulsi Dhakal ${ }^{3}$, Gopal Khanal ${ }^{3}$}

${ }^{1}$ Department of Internal Medicine, Pokhara Academy of Health Sciences, Pokhara

${ }^{2}$ Department of Orthopaedics, Gandaki Medical College, Pokhara

${ }^{3}$ Department of Radiology, Pokhara Academy of health sciences, Pokhara

\section{Correspondance:}

Buddhi Sagar Lamichhane, MD

Department of Internal Medicine,

Pokhara Academy of Health sciences,

Pokhara, Nepal

Email address:buddhis1999@gmail.com

Article received : May 312020

Article accepted : June 152020

\section{ABSTRACT}

Background: Stroke is one of the most common cause of morbidity and mortality worldwide. Approximately 50-85 percent of strokes are due to ischemic cerebral infarction and 7-27 percent to intracerebral hemorrhage. Since the incidence of stroke is increasing in our country, the study aims to identify various factors associated with stroke.

Materials and Methods: This is a retrospective study of 86 patients admitted in A \& B International Hospital, which is a private hospital located in Pokhara ,Nepal from 1 st January 2018 to $31^{\text {st }}$ December 2019. The case notes were taken from hospital record section and relevant data extracted and analyzed. Approval from the hospital management was taken prior to collecting the case notes. Patients below 18 years of age, stroke due to trauma were excluded. The data were collected, and were analyzed using SPSS version 20.0 software

Results: Of the total 86 patients studied, the age range was from 36 years to 94 years with mean age of 64.3 years. Mean age in ischemic stroke was 66.7 years and in hemorrhagic stroke was 54.8 years. Stroke is more common in men than female (2.3:1 ratio). Ischemic stroke accounted for 80.2 percent of cases and hemorrhagic stroke for 19.2 percent. Most common presentation included limb weakness, facial deviation and speech abnormality .Most common vascular territory involved was MCA territory infarction and small vessel strokes.

Conclusion: Stroke is prevalent in our country and the incidence rises with age .Ischemic stroke is more prevalent than hemorrhagic stroke. Mean age of hemorrhagic stroke is lower than that of ischemic stroke and hypertension is most commonly associated risk factor for both types of stroke.

Keywords: hemorrhage, ischemia, profile, retrospective, stroke 
Original Article

\section{INTRODUCTION}

The World Health Organization (WHO) definition of stroke is: "rapidly developing clinical signs of focal (or global) disturbance of cerebral function, with symptoms lasting 24 hours or longer or leading to death, with no apparent cause other than of vascular origin". ${ }^{2}$ Stroke is the second most common cause of death, accounting for 6.24 million deaths globally in 2015. It is also a leading cause of dependence and disability, ranked second worldwide. ${ }^{2}$ Approximately 50-85 percent of strokes are due to ischemic cerebral infarction and 7-27 percent to intracerebral hemorrhage. ${ }^{3}$ There are three main types of brain ischemia: Thrombosis, embolism and systemic hypo perfusion and two main subtypes of brain hemorrhage: intracerebral hemorrhage and subarachnoid hemorrhage. ${ }^{4}$ The lifetime risk of stroke for adult men and women aged $>25$ years is 25 percent. $^{5}$ Stroke risk is decreasing in high income countries, while it is increasing in low income countries. ${ }^{6-8}$

In a prospective study conducted in tertiary hospital of Nepal found hypertension most common risk factor and the most common ischemic stroke groups were MCA stroke (39.4\%) and small vessel stroke (17.2\%).The most common type of hemorrhage being basal ganglia hemorrhage which was present in $15 \%$ of patients. ${ }^{9}$ Most common risk factors are hypertension, diabetes, alcohol, smoking and dyslipidemia among elderly stroke patients. ${ }^{10-11}$ Since the incidence of stroke is increasing in our context, the study aims to identify various factors associated with stroke.

\section{MATERIALS AND METHODS}

This is a retrospective study of 86 patients admitted in A \& B International Hospital, which is a private hospital located in Pokhara ,Nepal from 1st January 2018 to 31st December 2019.The case notes were taken from hospital record section and relevant data extracted and analyzed. Approval from the hospital management was taken prior to collecting the case records.

\section{Exclusion criteria:}

Patients below 18 years of age Stroke due to trauma.
Medical Journal of Pokhara Academy of Health Sciences Vol. 3 Issue 1 Patients' medical records which were not showing CT or MRI confirmed diagnosis

The data were collected, and were analyzed using SPSS version 20.0 software.

\section{RESULTS}

86 cases of stroke case records admitted in A \& B International Hospital, which is a private hospital located in Pokhara, Nepal from $1^{\text {st }}$ January 2018 to $31^{\text {st }}$ December 2019 were studied and evaluated for clinical profile and risk factors.

\section{Incidence of age}

The age range was from 36 years to 94 years with mean age of $64.3 \pm 12.7$ years. Mean age in ischemic stroke was $66.7 \pm 11.8$ years and in hemorrhagic stroke was $54.8+11.8$ years.

Table 1: Age and Sex distribution

\begin{tabular}{cccc} 
Age(Years) & Male & Female & Total \\
$31-40$ & 2 & 0 & $2(2.3 \%)$ \\
$41-50$ & 8 & 5 & $13(15.1 \%)$ \\
$51-60$ & 16 & 1 & $17(19.7 \%)$ \\
$61-70$ & 17 & 8 & $25(29.0 \%)$ \\
$71-80$ & 13 & 9 & $22(25.5 \%)$ \\
$\geq 81$ & 4 & 3 & $7(8.1 \%)$ \\
Total & 60 & 26 & $86(100 \%)$ \\
\hline
\end{tabular}

Table 1 shows that stroke prevalence is more prevalent in males $(69.8 \%)$ than in females $(30.2 \%)$. Most of the patients fall in age group 60-80 years.

\section{Table 2: Associated risk factors}

\begin{tabular}{lcc} 
Risk factors & $\begin{array}{c}\text { Number } \\
(\mathbf{N = 8 6 )}\end{array}$ & Percentage \\
\hline Hypertension & 62 & 72.1 \\
Smoking & 42 & 48.8 \\
\hline Dyslipidemia & 22 & 25.6 \\
\hline Diabetes mellitus & 15 & 17.4 \\
\hline Atrial fibrillation & 11 & 12.8 \\
\hline Past history of CAD & 4 & 4.7
\end{tabular}

Table 2 shows that hypertension is the most common risk factor present in the studied population. 
Original Article

Table 3: Symptoms at presentation

\begin{tabular}{|c|c|c|c|}
\hline \multicolumn{2}{|l|}{ Symptoms } & $\begin{array}{l}\text { aber } \\
86)\end{array}$ & Percentage \\
\hline \multicolumn{2}{|l|}{ Hemiparesis } & 1 & 94.2 \\
\hline \multicolumn{2}{|c|}{ Facial deviation } & 8 & 67.4 \\
\hline \multicolumn{2}{|c|}{ Speech abnormalities } & 8 & 67.4 \\
\hline \multicolumn{2}{|l|}{ Headache } & 3 & 9.3 \\
\hline \multicolumn{2}{|l|}{ Vomiting } & 7 & 8.1 \\
\hline \multicolumn{2}{|c|}{ Loss of consciousness } & 7 & 8.1 \\
\hline \multicolumn{2}{|l|}{ Ataxia } & & 1.2 \\
\hline \multicolumn{4}{|c|}{$\begin{array}{l}\text { Table } 3 \text { shows that most of the patients presented with } \\
\text { hemiparesis, facial deviation and speech abnormalities. }\end{array}$} \\
\hline \multicolumn{2}{|l|}{ Type of stroke } & $\begin{array}{c}\text { Number } \\
(\mathrm{N}=86)\end{array}$ & Percentage \\
\hline & Thrombotic & 58 & 67.4 \\
\hline Ischemic & Cardioembolic & 11 & 12.8 \\
\hline Hemorrhagic & & 17 & 19.8 \\
\hline
\end{tabular}

Table 4 shows that ischemic stroke which is thrombotic in origin is the most common type in the studied population.

Table 5: Topographic or vascular territory distribution of stroke

\begin{tabular}{lccc}
\hline $\begin{array}{l}\text { Type of } \\
\text { stroke }\end{array}$ & $\begin{array}{c}\text { Site or vascular } \\
\text { territory }\end{array}$ & $\begin{array}{c}\text { Number } \\
(\mathrm{N}=86)\end{array}$ & Percentage \\
\hline & $\begin{array}{c}\text { MCA territory } \\
\text { and small vessel } \\
\text { strokes }\end{array}$ & 66 & 76.8 \\
& ACA territory & 1 & 1.2 \\
Ischemic & PCA territory & 2 & 2.3 \\
&
\end{tabular}


Original Article

risk among former smokers largely disappeared two to four years after cessation. ${ }^{14-15}$

Most common symptoms are hemiparesis in 81 patients (94.2 percent), facial deviation (67.4 percent) and speech abnormality (67.4 percent) and type of stroke observed was ischemic (80.2 percent) and hemorrhagic (19.8 percent). A retrospective study of all new patients managed for stroke in the medical ward of GMERS medical college and hospital, Gandhinagar, Gujarat from January1, 2012 to December 31, 2013 showed hemiparesis most common symptom in 72.6 percent patients, ischemic stroke (74.6percent) and hemorrhagic (22.9 percent). ${ }^{16}$

The study showed that most common vascular territory in ischemia is MCA territory and small vessel strokes and most common sites of hemorrhagic stroke are intraparenchymal, thalamus, basal ganglia and putamen as seen in most of the studies.

\section{CONCLUSION}

Stroke is prevalent in our country. The incidence rises with age .Ischemic stroke is more prevalent than hemorrhagic stroke. Mean age of hemorrhagic stroke is lower than that of ischemic stroke and hypertension is most commonly associated risk factor for both types of stroke. So proper hypertension treatment and BP control seems to be the most important preventive strategy for stroke.

\section{Limitations of the study}

1. Sample size is small

2. Some data in the case notes might not be accurate

3. Speech abnormality includes slurring of speech and aphasia .Incidence of aphasia could not be elicited.

\section{Conflict of interest: None}

\section{References}

1. WHO MONICA Project Principal Investigators. The World Health Organization MONICA Project (monitoring trends and determinants in cardiovascular disease): a major international
Medical Journal of Pokhara Academy of Health Sciences Vol. 3 Issue 1 collaboration. Journal of clinical epidemiology. 1988 Jan 1;41 (2):105-14.

2. Global, regional, and national burden of neurological disorders, 1990-2016: a systematic analysis for the Global Burden of Disease Study 2016. The Lancet Neurology. 2019;18(5):45980 .

3. Feigin VL, Lawes CM, Bennett DA, BarkerCollo SL, Parag V. Worldwide stroke incidence and early case fatality reported in 56 populationbased studies: a systematic review. The Lancet Neurology. 2009;8(4):355-69.

4. Caplan LR. Basic pathology, anatomy, and pathophysiology of stroke. In: Caplan's Stroke: A Clinical Approach, 4th ed, Saunders Elsevier, Philadelphia 2009. p.22.

5. Feigin VL, Nguyen G, Cercy K, Johnson CO, Alam T, Parmar PG, et al. Global, Regional, and Country-Specific Lifetime Risks of Stroke, 1990 and 2016. The New England journal of medicine. 2018;379(25):2429-37.

6. Madsen TE, Khoury JC, Leppert M, Alwell K, Moomaw CJ, Sucharew H, et al. Temporal Trends in Stroke Incidence Over Time by Sex and Age in the GCNKSS. Stroke. 2020;51(4):1070-6.

7. Feigin VL, Forouzanfar $\mathrm{MH}$, Krishnamurthi R, Mensah GA, Connor M, Bennett DA, et al. Global and regional burden of stroke during 1990-2010: findings from the Global Burden of Disease Study 2010. Lancet (London, England). 2014;383(9913):245-54.

8. Vangen-Lønne AM, Wilsgaard T, Johnsen SH, Løchen ML, Njølstad I, Mathiesen EB. Declining Incidence of Ischemic Stroke: What Is the Impact of Changing Risk Factors? The Troms $\varnothing$ Study 1995 to 2012. Stroke. 2017;48(3):544-50

9. Dhungana K. Demographic characteristics of stroke in a tertiary care hospital in Nepal. Nepal 
Journal of Neuroscience. 2018;15(3):54-8.

10. Habibi-Koolaee M, Shahmoradi L, Niakan Kalhori SR, Ghannadan H, Younesi E. Prevalence of Stroke Risk Factors and Their Distribution Based on Stroke Subtypes in Gorgan: A Retrospective Hospital-Based Study-2015-2016. Neurology research international. 2018;2018:2709654.

11. Sylaja PN, Pandian JD, Kaul S, Srivastava MVP, Khurana D, Schwamm LH, et al. Ischemic Stroke Profile, Risk Factors, and Outcomes in India: The Indo-US Collaborative Stroke Project. Stroke. 2018;49(1):219-22.

12. Maskey A, Parajuli M, Kohli SC. A study of risk factors of stroke in patients admitted in Manipal Teaching Hospital, Pokhara. Kathmandu University medical journal. 2011;9(36):244-7.

13. Petty GW, Brown RD, Jr., Whisnant JP, Sicks JD, O'Fallon WM, Wiebers DO. Ischemic stroke subtypes: a population-based study of incidence and risk factors. Stroke. 1999;30(12):2513-6

14. Shah RS, Cole JW. Smoking and stroke: the more you smoke the more you stroke. Expert review of cardiovascular therapy. 2010;8(7):917-32.

15. Kawachi I, Colditz GA, Stampfer MJ, Willett WC, Manson JE, Rosner B, et al. Smoking cessation and decreased risk of stroke in women. Jama. 1993;269(2):232-6.

16. Vaidya C, Majmudar D. A retrospective study of clinical profile of stroke patients from GMERS Medical College and Hospital, Gandhinagar, Gujarat. International Journal of Clinical Trials. 2014:62-6 